\title{
Problem-Based Learning in Communication Systems: Student Perceptions and Achievement
}

\author{
John E. Mitchell, Member, IEEE, Brian Canavan, and Jan Smith
}

\begin{abstract}
The paper presents a curriculum design for, and subsequent evaluation of, a communications systems course using problem-based learning (PBL) as the instructional methodology. It details the rationale for implementing PBL as well as reporting intended learning outcomes and assessing the students' achievements.
\end{abstract}

Index Terms-Communication engineering education, education, electrical engineering education, electronics engineering education, problem solving.

\section{INTRODUCTION}

$\mathbf{R}$ EPORTS published by industrial bodies and professional institutions highlight the need for universities to equip graduates with personal and transferable skills to prepare them for careers in engineering; see, for example, [1] and [2]. An early example was the report produced by an Industry Working Party formed by the Institution of Engineering and Technology-IET (formerly the Institution of Electrical Engineers, IEE). This report emphasized the need for engineering graduates to be able to engage in lifelong learning and be highly proficient in problem solving, communications, and team-working skills. In response to this report, three U.K. universities (University College London (UCL), University of Manchester, and University of Bristol) supported by the IET sought funding to pilot problem-based learning (PBL) to strengthen student attainment in these areas.

This paper reports on curriculum development within one of these universities and presents student perceptions and external evaluation data after four years of running the course.

\section{Module Design Rationale}

Electronic engineering education in U.K. higher education has remained largely conventional [3] in the face of many changes in student and employer expectations [4], [5]. The drive to diversify outcomes from a traditional electronic engineering degree program led to an investigation of a range of approaches to curriculum design and delivery. PBL emphasizes

Manuscript received March 27, 2009; revised October 02, 2009. This work was supported by the Police Information Technology Office, Higher Education Funding Council for England (HEFCE), the Institution of Engineering and Technology (IET).

J. E. Mitchell is with the Department of Electronic and Electrical Engineering, University College London, London WC1E 7JE, U.K. (e-mail: j.mitchell@ee. ucl.ac.uk).

B. Canavan is with the Robert Clark Centre for Technological Education, University of Glasgow, Glasgow G3 6NH, U.K.

J. Smith is with the Centre for Academic Practice and Learning Enhancement (CAPLE), University of Strathclyde, Glasgow G1 1QE, U.K.

Digital Object Identifier 10.1109/TE.2009.2036158 transferable skills development alongside disciplinary content coverage and, therefore, is one approach to satisfying the multiple demands now made of undergraduate education.

Designing PBL courses can be challenging as lecturers integrate subject material, transferable skills, and new teaching methods. A guiding principle comes from focusing on what students are expected to know or do on completion of the module. Once such objectives are defined, a range of activities can be considered that allows students to progress toward the preferred outcomes. These activities should be designed to build on students' prior learning and experiences and should be directly related to the assessment objectives in a constructively aligned way [6]. With this alignment in place, consideration can then be given to the appropriate range of relevant material that needs to be included in the course design and resources.

\section{IMPLEMENTATION MODEL}

There are many models of PBL implementation [7]. Sections IV-VIII highlight three major choices that must be made when implementing this approach: how much of the curriculum will be changed, the topics that constitute the new curriculum, and assessment methods. Based on [8], the approach taken was that of a "single module" mode, where PBL is dropped into a predominantly traditional lecture-based syllabus. This is a cost-effective approach in terms of resourcing, but can lead to conflict as students are asked to move from one learning paradigm to another. As is shown in [8], teaching can still be delivered conventionally before students progress to problem-solving activities (a form of project-based learning [9]). In other models, the conventional teaching resource is withdrawn completely and replaced by a "pure" PBL approach, the model adopted in the study reported here.

The elective course in which PBL was implemented was a third-year, Communication Systems II module that runs over one term (12 weeks) and had, until the 2004-2005 academic session, been delivered conventionally through lecture and examination. Historically, the course has focused on communications system/applications, drawing on the fundamental concepts taught in the first-year Communications Systems I module and the second-year Optoelectronics module. These attributes made it an ideal candidate for instruction through PBL, allowing students to develop new skills and acquire new knowledge, but building on a framework of familiar concepts.

No formal lectures were planned or delivered, except for one introduction session and some instruction on literature searching. This differs from some other approaches that have also been termed PBL [7]. The main form of staff contact was through time-tabled Facilitation sessions, amounting to 2 to 
TABLE I

SUMMARY OF PROBLEM BRIEFS GIVEN TO STUDENTS

\begin{tabular}{|c|c|c|}
\hline Summary of Problem Brief & Technical Knowledge & Engineering Specific Skills \\
\hline $\begin{array}{l}\text { Produce a reference wiki for an } \\
\text { engineering team working on a } \\
\text { radio communications project }\end{array}$ & $\begin{array}{l}\text { Radio Propagation, Noise in } \\
\text { Radio Systems }\end{array}$ & $\begin{array}{l}\text { Ability to specify search criteria for } \\
\text { scientific/ engineering literature, } \\
\text { evaluate the information, } \\
\text { synthesize into a clear and concise } \\
\text { form. }\end{array}$ \\
\hline $\begin{array}{l}\text { Design a system to send and } \\
\text { receive two channels of } \\
\text { Composite Video from a } 75 \Omega \\
\text { feed over a digital link. }\end{array}$ & $\begin{array}{l}\text { Sampling, quantization, filter } \\
\text { specification, digital signals, } \\
\text { multiplexing / demultiplexing }\end{array}$ & $\begin{array}{l}\text { Ability to analyze, synthesize and } \\
\text { evaluate specification documents } \\
\text { and component datasheets }\end{array}$ \\
\hline $\begin{array}{l}\text { Design a radio link operating at } \\
50 \mathrm{Mbit} / \mathrm{s} \text { over } 275 \mathrm{~m} \text { given the } \\
\text { components specified. }\end{array}$ & $\begin{array}{l}\text { Digital signals, signal } \\
\text { design, error coding, digital } \\
\text { modulation, noise }\end{array}$ & $\begin{array}{l}\text { Ability to analyze specification } \\
\text { documents and follow good } \\
\text { practice in engineering design to } \\
\text { create a prototype }\end{array}$ \\
\hline $\begin{array}{l}\text { Specify the components to form } \\
\text { three optical links. }\end{array}$ & $\begin{array}{l}\text { Fibre } \\
\text { and Reciples, } \\
\text { Receivers, Oetectors } \\
\text { Systems. }\end{array}$ & All of the above \\
\hline
\end{tabular}

$3 \mathrm{~h}$ a week, with a loading bias toward the beginning of the problem cycle. The students worked in small groups of five or six formed through a combination of staff and self-selection. During the course of the term, the groups were presented with four problem briefs, ranging from two to four weeks' duration.

\section{Curriculum}

The second decision relates to selecting appropriate topics and skills for the new curriculum. Existing syllabi may need rationalization to give sufficient time to the additional skills agenda. In this study, some rationalization of the curriculum did occur, and the transferable skills element was expressly articulated as an integral part of the course. The reasoning for the specific curriculum development decisions are explored more fully elsewhere [8], [9]. The eventual module design comprised three distinctive areas of communication systems: radio, digital and optical, and the relevant transferable skill set. The parameters for writing the problem, or trigger material, were then extracted from this high-level design. In addition, a set of generic skills were identified as:

- Criticality-Working with incomplete information.

- Creativity-Innovative solutions.

- Problem solving - Locating and reframing problems in the wider context.

- Academic development-Oral/written communication, information-handling skills.

- Personal and professional development-Teamwork, time management, collaboration.

Table I demonstrates how these were formed into the four problem briefs. Trigger material was developed to provide coverage of a set of technical knowledge areas and a broad range of key skills. In terms of engineering-specific skills, problems increased in coverage over time, with early problems expecting only literature evaluation skills, while the last problem expected all three skill areas to be addressed. These skills were specifically identified in the assessment criteria for each problem. An example of the trigger material used in this final problem is given below and in Fig. 1.

MEMO: Request for Tenders; Customer Access System.
We are bidding for a contract to build a system that will offer an end-to-end solution to transport data from customer access points to a central office site. The system will use existing multiplexer units, but you are required to specify optical interconnects that are required between the various units. You are required to design three optical links (details below). The optical link is defined as only the optical components; design of the electrical driving circuitry is not required.

Link 1: Customer Units output a signal at the STM-1 rate. These signals must be connected to the level 2 multiplexer unit over an optical link of a maximum length of $10 \mathrm{~m}$. Many of these may be together in the network cabinet on each floor.

Link 2: The level 2 multiplexers output signals at the STM-4 rate and are connected to level 3 multiplexers in the basement of the customer premises, which is a maximum distance of $500 \mathrm{~m}$ from the level 2 multiplexer.

Link 3: The central office will take signals at the STM-64 rate from the customer site to the central office up to $80 \mathrm{~km}$ away.

This is a competitive tender, so proposals should make efficient use of the components chosen and demonstrate that a capacity upgrade of the link 3 section is possible to meet future customer demands. You may assume that our multiplexers are lossless and noiseless.

\section{ASSESSMENT}

The third major decision related to the methods of assessment used. De Graff highlighted the considerable impact that assessment has on the PBL process and suggested that exponents of the approach develop assessment methods that promote intrinsic motivation and reward processes as well as outcomes [10]. This is a departure from a common model of assessment as purely a form of summative evaluation of student attainment. To achieve the dual aims of motivating students and rewarding diverse contributions to open-ended problems, while providing a rigorous and defendable framework for grading, portfolios were 


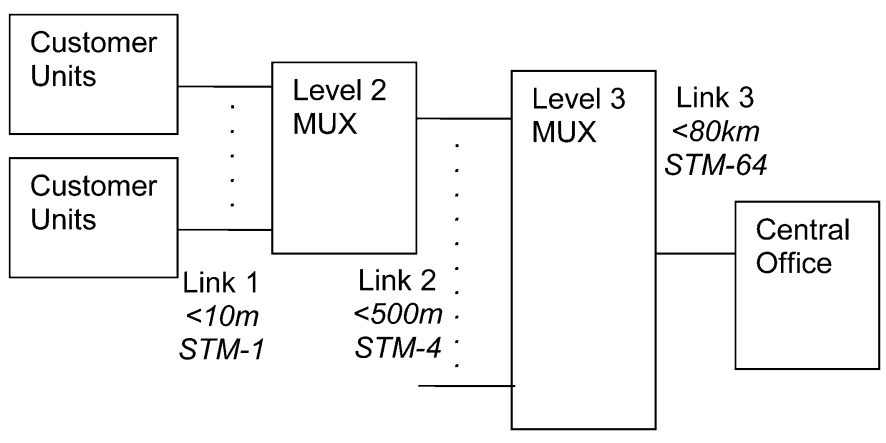

Fig. 1. System specification given to students.

used, incorporating a two-stage submission process. At the end of each problem, problem solutions were submitted for formative feedback including indicative grades. Summative assessment occurs at the end of the program when a complete set of (revised) group problem solutions are submitted along with an individual narrative detailing the contributions and individual achievements of each student. This introduced two new concepts to students. The first is the use of directly relevant feedback. Frequently, feedback is given during a course of study, but much of it is post-grading, where it is often ignored, or difficult to translate to subsequent assessment. The second new challenge was the reflective narrative that presented a very different written style to those commonly required of students. It also presented challenges for staff, in particular in evaluating the skills elements. Here, guidelines produced by engineering accreditation bodies can be useful, but the professional experience of the staff member involved was found to be most important.

\section{EVALUATION}

There can be a tension between high academic standards and what is often termed the "economic imperative" of a transferable skills approach. This difficulty can lead to dissatisfaction by all stakeholders if it is not clear what has been achieved. It is important to clarify learning objectives and assessment requirements in relation to skills and knowledge. At the beginning of this curriculum development process, very few examples relating to electronic engineering could be found in the literature to use as a template, although a number of case studies have emerged in the last few years [11], [12]. Without such exemplars showing the strengths and weaknesses of PBL, it was difficult to determine how success might be defined and measured. It was important, in the context of the single-module implementation model, that appropriate plans were put in place to measure the effectiveness of the PBL approach.

In order to satisfy those stakeholders with an interest in the highest academic standards, and those with a focus on enhancing graduate skills, two approaches were taken to evaluation: one strand focused on staff and institutional concerns [8], [9], while the second identified and measured student achievement. This second level of activity was carried out by an external evaluation team, and the results are reported in Section VII. In this section, key lessons are summarized for staff considering implementing PBL, followed by the students' perceptions and achievement.

\section{A. Staff Perceptions}

To experienced professional engineers, a wide range of tasks with relevant real-world applications appear to be suitable for use as trigger material. However, although many of these would make excellent term-long projects for students, short timescales and tightly defined learning requirements demand very careful design of the problem material. To adequately cover the topics specified, in both appropriate breadth and depth, is often the most challenging part of the design process, with either being relatively easy to cover individually, but achieving both being difficult to do within a single problem. Strategies such as the three-part problem described above or providing sample systems to be analyzed and refined both work well to get coverage of a topic, where a simple design exercise might see the group very quickly focus on a single system type. Also staging problems can be useful, with milestones set for specifications or additional information provided to alter the focus of the groups.

A point of particular interest, the significance of which was overlooked at first, is the impact that the language used to define the problem has on the way students interpret what is being asked of them. Terms that many may use interchangeably can alter the students' perception of the problem significantly. In early problems students would home in on the known terms and seek to capture as much information as possible, with important concepts being overlooked if not expressed in familiar terms.

For most staff, the change in role from instructor to facilitator is a difficult transition to make. In particular, facilitating open-ended problems is often hard, where the goal is to enable learning and problem solving without guiding the students toward a "right answer." Although no model answers where proposed when problems were set, some simple calculations were obviously completed on a possible solution to check that the problem was tractable. In this study, post-doctoral researchers assisted with facilitation. Deliberately, these facilitators where given no prior sight of the problem specification and, therefore, only benefited from increased engineering experience. Although they were researchers in the communications area, they were not expected to be experts across all the areas covered. This worked well by enabling facilitators to assist groups in applying a range of approaches rather than offering targeted guidance that inadvertently undermines students' problem-solving efforts.

\section{B. Student Perceptions}

Toward the end of the PBL module, each participating student was asked to complete a questionnaire that asked about their perceptions of PBL and explored some of the issues encountered during the module. This was supplemented by a number of focus groups intended to provide a deeper insight into the issues encountered. A total of seven student focus groups were conducted over a three-year period. The questionnaire was also administered over the same three years, with a total of 53 responses gathered from participants. The findings discussed in the following sections are based on combinations of data obtained via a number of methods employed over the course the evaluation. In total, these included staff interviews, participant/nonparticipant observation, as well as the measures already outlined. Student comments have been used to exemplify various phenomena 
as they emerged from the data. While some of the methods employed in the evaluation demanded an interpretive approach to the data, the authors have sought to triangulate findings across multiple methods in an attempt to ensure reliability of the claims made in the discussion.

The results obtained from the questionnaire, shown in Table II indicated that the students were generally well disposed to PBL. However, discussion with them during the focus groups indicated that recognition of positive attributes appeared somewhat begrudging due to what was perceived as additional burdens inherent in PBL. The questionnaire data was compared over the three years of the evaluation to establish its reliability and to assess any major shifts in perception. There was a remarkable level of consistency observed over the three years, with mean values remaining relatively stable from year to year (Fig. 2).

It was clear from the responses gathered that the shift from what was a largely transmission-based model of learning to a problem-based approach took some getting used to for many of the students, particularly in relation to time management and information handling and filtering. The gathering and critical appraisal of information associated with PBL promoted a degree of insecurity among many of the students during early problems as they acclimatized to the new approach. It became apparent that many of the students considered PBL from a very strategic perspective, which was largely driven by their level of confidence in being able to successfully achieve the learning outcomes outlined in each problem brief and ultimately with the final grade that they hoped to achieve. During a number of the focus groups, participants expressed feelings of insecurity, which largely appeared in the form of grade anxiety, a phenomenon that has been recognized in other studies of PBL [13], [14]. This could be attributed to the fact that students were attempting to map their tried and tested approaches to learning based on final examination to a new and more open-ended approach.

Further evidence of the kind of strategic thinking employed by many of the students was observed in their responses to the questionnaire statement "I prefer to learn through conventional lectures." The large proportion of students who responded "neutral" to this statement may indicate that they were somewhat torn between the intellectual and time demands associated with PBL and the acknowledgment of certain intrinsic benefits associated with the approach. This view is supported by student comments taken from two of the focus groups, which exemplify the more general student view. One student who observed that PBL had provided her with a very different learning experience to that encountered during conventional lecture-based modules characterized the conflicting feelings exhibited more generally. She candidly pointed out that she would have typically concentrated her study toward the end-of-year exam during conventionally taught modules, knowing this to be a very strategic approach, while also recognizing the benefit of PBL by asserting that "with PBL I'm actually learning to understand it (theory) better because I'm having to apply the knowledge." Another highlighted the shift in approach to the need for greater discrimination in the information gathered: "You had to sort through information to find what was relevant to you."

Unsurprisingly, time management proved to be a major issue with students who overwhelmingly agreed that a problem-based approach took up more of their time than traditionally taught courses (96\% agree/strongly agree). While teaching staff were generally content that the amount of time required to complete a given problem was consistent with their own notional workload guidelines, the students felt that they were required to invest a disproportionate amount of time on PBL compared to the commitment required for a traditionally taught module. This was perhaps the most common point of discussion during the focus groups, with students estimating that they were spending between 10 and $15 \mathrm{~h}$ per week on PBL-related activity, a figure that they regarded as being significantly higher than time spent on an equivalent traditionally taught module.

Apart from the issues of time and approach, students also expressed concern over group work and assessment requirements. The dynamic within a group can have a major impact on the learning experience of individual students [15]. Few students had previous experience of working in groups, and while a small number expressed reservations about the equity and fairness of group assessment, they overwhelmingly regarded working in a group as a positive experience that they felt was very relevant to them in their future careers.

It was clear from observational and focus group evidence that a PBL approach demanded more complex approaches to communication and information management from the students. This included the use of e-mail and mobile communications as well as the University's virtual learning environment. The need to share the gathering, analysis, and dissemination of information was new to most students, demanding a fair degree of sophisticated project management and communication within and sometimes between groups. It also demanded that they found ways in which they could operate effectively outside time-tabled facilitation sessions. One student comment provided an interesting insight into the shift in learner engagement and mind-set that can be achieved through the introduction of PBL: "Even when we didn't have a meeting arranged, we'd end up talking about it (PBL) anyway."

It also emerged over the course of the evaluation that potential employers were rather well-disposed to the skills developed through PBL, as recounted by a number of students who had participated in interviews or work placements with various employers during which their experiences of PBL had been discussed. It was clear from these discussions that employers placed significant value on the generic skills developed by PBL, such as teamwork, problem solving, and communication skills. This recognition acted as an important validation factor for the students, allowing them to reflect upon the relationships between what they were learning and the methods employed and how these related to their future employability.

One particular student recounted the positive response he had received from potential employers during a number of interviews for various engineering internships when he discussed his PBL experience: "Some people were quite surprised because they were not aware of such teaching methods in engineering degrees."

\section{STUDENT ACHIEVEMENT}

Student assessment scores were analyzed over a seven-year period in order to determine whether there was any observ- 
TABLE II

PERCEPTION QuestionNAIRE RESPONSES ( $N=53$ )

\begin{tabular}{|c|c|c|c|c|c|}
\hline Questionnaire Statements & $\begin{array}{l}\text { Strongly } \\
\text { disagree }\end{array}$ & Disagree & Neutral & Agree & $\begin{array}{l}\text { Strongly } \\
\text { agree }\end{array}$ \\
\hline $\begin{array}{l}\text { 1. I like problem-based } \\
\text { learning. }\end{array}$ & $3(6 \%)$ & $5(9 \%)$ & $13(24 \%)$ & $30(57 \%)$ & $2(4 \%)$ \\
\hline $\begin{array}{l}\text { 2. I feel that I learn more in } \\
\text { problem-based learning than } \\
\text { conventional lecture-based } \\
\text { courses. }\end{array}$ & $0(0 \%)$ & $10(19 \%)$ & $16(30 \%)$ & $23(43 \%)$ & $4(7 \%)$ \\
\hline $\begin{array}{l}\text { 3. Problem-based learning } \\
\text { takes up more of my time than } \\
\text { conventional lecture-based } \\
\text { courses. }\end{array}$ & $0(0 \%)$ & $0(0 \%)$ & $2(4 \%)$ & $12(23 \%)$ & 39 (73\%) \\
\hline $\begin{array}{l}\text { 4. I have to take more } \\
\text { responsibility for my learning in } \\
\text { problem-based learning. }\end{array}$ & $0(0 \%)$ & $1(2 \%)$ & $7(13 \%)$ & $23(43 \%)$ & $22(41 \%)$ \\
\hline 5. I enjoy working in a group. & $1(2 \%)$ & $2(4 \%)$ & $14(26 \%)$ & $32(60 \%)$ & $4(7 \%)$ \\
\hline $\begin{array}{l}\text { 6. I clearly understood the } \\
\text { problem(s) given to me. }\end{array}$ & $1(2 \%)$ & $7(13 \%)$ & $23(43 \%)$ & $17(32 \%)$ & $5(9 \%)$ \\
\hline $\begin{array}{l}7 . \text { I easily understood what } \\
\text { was required of me in } \\
\text { answering the problem(s). }\end{array}$ & $0(0 \%)$ & $11(21 \%)$ & $27(51 \%)$ & 14 (26\%) & $1(2 \%)$ \\
\hline $\begin{array}{l}\text { 8. I was happy with the level of } \\
\text { support provided by staff } \\
\text { during the module. }\end{array}$ & $2(4 \%)$ & $5(9 \%)$ & $13(24 \%)$ & 28 (53\%) & $5(9 \%)$ \\
\hline $\begin{array}{l}\text { 9. I prefer to learn through } \\
\text { conventional lectures. }\end{array}$ & $0(0 \%)$ & $8(15 \%)$ & $24(45 \%)$ & $15(28 \%)$ & $6(11 \%)$ \\
\hline $\begin{array}{l}10 . \text { I would like to learn this } \\
\text { way again. }\end{array}$ & $3(6 \%)$ & $5(9 \%)$ & $21(40 \%)$ & $22(42 \%)$ & $2(4 \%)$ \\
\hline $\begin{array}{l}\text { 11. Problem-based learning } \\
\text { has made me better at } \\
\text { knowing how to find and use } \\
\text { information in my learning. }\end{array}$ & $0(0 \%)$ & $1(2 \%)$ & $6(11 \%)$ & 28 (53\%) & $18(34 \%)$ \\
\hline
\end{tabular}

able difference in attainment between the conventionally taught module and its PBL replacement (Table III). It is important to note that no direct comparison is implied. The nature of the assessment regime changed radically from the conventional to the PBL course, so drawing conclusions from a direct comparison of the raw marks is not reliable, but the data are presented here to summarize student achievement. However, other features of the assessment and evaluation, reported below, are notable.

The comparison of results shown in Table III (average exam grade pre-PBL and average portfolio mark for PBL) indicates a slight upward trajectory in the mean assessment score from the conventional to PBL module, although with the exception of the 2003-2004 session, this was within a single grade band (less than 10\%). More significant was the complete drop-off in student failure rate from a mean of around $18 \%$ over the three traditionally taught years to zero for the subsequent four PBL years. While it was clear that the introduction of PBL eliminated failure entirely on the module, it did prompt a degree of reflection among participating staff in relation to the methods of assessment employed and their ability to effectively assess the desired learning outcomes. There is no doubt that the shift from a purely summative end-of-year examination to the use of assessment tools that rewarded the problem solving process and collaboration, and introduced elements of continuous and formative assessment, contributed significantly to the elimination of failure. The authors recognize that striking the correct balance between assessment of subject knowledge and generic skills may require some further work based on these findings.

The inclusion of a 10-min oral examination (viva) in the assessment regime demanded a significant investment of staff time, but proved useful as a form of assessment that demanded a holistic approach to problem solving among and between student groups and promoted the assessment of process as well as outcome. A comment made by one of the students during a focus group highlighted the effectiveness of the viva in developing a shared learning experience despite the fact that it was accompanied by a degree of insecurity:

"I think that is a bit of a problem because there are bits of the problem that someone wouldn't know...but we've got a viva. That means that everyone needs to know everything; so at the moment I don't know every bit of what everyone has done, but I think that by the time the viva comes round I'll have to make an effort to find out what's going on."

A pre/post-intervention confidence log was administered to participating students during the 2004-2005 and 2005-2006 


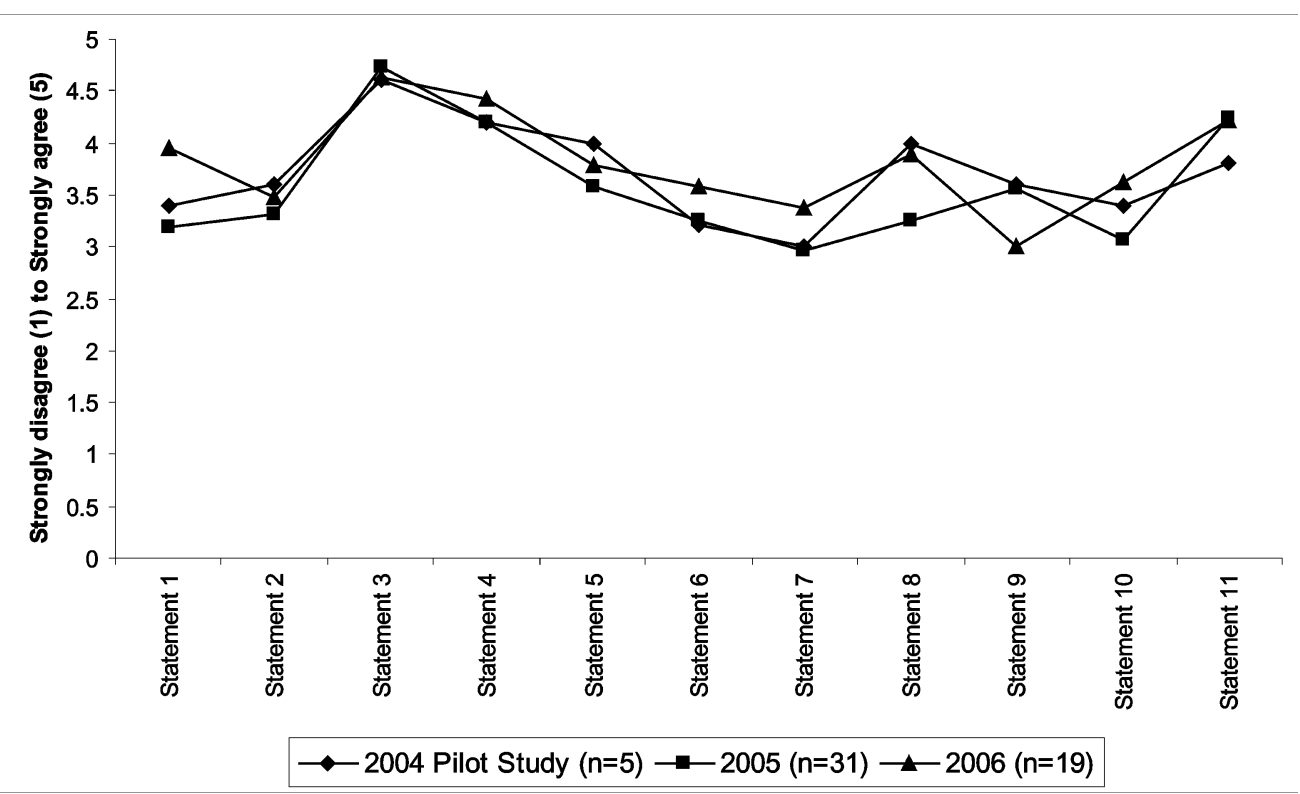

Fig. 2. Comparison of questionnaire responses.

TABLE III

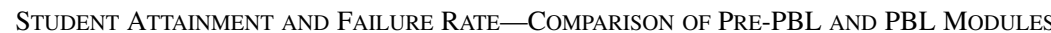

\begin{tabular}{|l|c|c|c|c|c|c|c|}
\hline & $\begin{array}{c}\text { 2001/02 } \\
\text { (Pre-PBL) }\end{array}$ & $\begin{array}{c}\text { 2002/03 } \\
\text { (Pre-PBL) }\end{array}$ & $\begin{array}{c}\text { 2003/04 } \\
\text { (Pre-PBL) }\end{array}$ & $\begin{array}{c}\text { 2004/05 } \\
\text { (PBL) }\end{array}$ & $\begin{array}{c}\text { 2005/06 } \\
\text { (PBL) }\end{array}$ & $\begin{array}{c}\text { 2006/07 } \\
\text { (PBL) }\end{array}$ & $\begin{array}{c}\text { 2007/08 } \\
\text { (PBL) }\end{array}$ \\
\hline $\begin{array}{l}\text { Mean Assessment } \\
\text { Score (\%) }\end{array}$ & 60 & 63 & 51 & 64 & 68 & 64 & 63 \\
\hline $\begin{array}{l}\text { Student Failure } \\
\text { Rate (\%) (<40\% } \\
\text { mark) }\end{array}$ & 16 & 20 & 17 & 0 & 0 & 0 & 0 \\
\hline
\end{tabular}

sessions to evaluate individuals' perceptions of their progress over a number of topics covered by the module (Table IV). Identical logs were completed at the start and end of the module. A total of 28 students completed both logs, fewer than had been anticipated perhaps due to the fact that the logs were administered online. While the logs themselves do not provide the study with an objective measure of learning, their strength lies in their ability to provide a platform for student personal reflection and judgment of their learning based on the topics covered by the module. The results for the sample showed an increase in mean confidence for each of the topics covered. While this increase was somewhat modest for a number of the topics, the post-PBL log results did indicate that the students had moved toward the "somewhat confident/confident" categorization, with the exception of one topic that remained within the "not very confident/somewhat confident" category. Overall, confidence levels increased from a mean value of 3.46 to one of 2.50 across the 11 topics. It was clear from the pre-PBL confidence log results that the students had a fair degree of prior knowledge of some of the topics covered, which to some extent accounted for the modest increase in overall confidence. During the focus groups, students' comments relating to confidence largely revolved around their ability to discriminate effectively between various forms of information and ensure that they were able to complete the assessable outcomes successfully. In this regard, confidence was observed to be very much related to achievement, highlighting the need to ensure that assessment methods promote learner confidence by recognizing the multiplicity of solutions available for a given problem.

\section{DISCUSSION}

Wenger's assertion [16] that the institutional view of learning is still one that is largely defined by individual endeavor, where collaboration is seen as subversion and where the process is driven by teaching, is one that will no doubt resonate with many who have striven to develop new and innovative ways to promote learning. With this in mind, the introduction of a problembased approach to learning and teaching can be demanding in terms of faculty and institutional support. However, the development of a curriculum that is sensitive to the issues discussed in this paper can prove very rewarding for both staff and students alike.

The argument for approaches that promote collaboration among learners and offer a rich contextualization of theory through process-driven application is a seductive one. This highlights the benefits asserted by Pask in his seminal theory 
TABLE IV

Comparison of Mean VAlues of StUdent CONFIDENCE PRE/Post-PBL $(N=28)$

\begin{tabular}{|c|c|c|}
\hline Topic & $\begin{array}{l}\text { Pre- } \\
\text { PBL } \\
\text { Mean }\end{array}$ & $\begin{array}{l}\text { Post- } \\
\text { PBL } \\
\text { Mean }\end{array}$ \\
\hline $\begin{array}{l}\text { How confident are you in your knowledge of the } \\
\text { general characteristics of semiconductor lasers - } \\
\text { compared with LEDs? }\end{array}$ & 3.11 & 2.39 \\
\hline $\begin{array}{l}\text { How confident are you in your knowledge of the } \\
\text { characteristics of photodetectors? }\end{array}$ & 2.89 & 2.71 \\
\hline $\begin{array}{l}\text { How confident are you in your knowledge of the } \\
\text { characteristics of single mode and multimode silica } \\
\text { optical fibers? }\end{array}$ & 3.07 & 2.04 \\
\hline $\begin{array}{l}\text { How confident are you in your knowledge of the } \\
\text { characteristics of plastic optical fibers? }\end{array}$ & 4.07 & 2.93 \\
\hline $\begin{array}{l}\text { How confident are you in your knowledge of the } \\
\text { structure and operation of different classes of laser - } \\
\text { DFB, Fabry-Perot, VCSEL? }\end{array}$ & 4.50 & 2.93 \\
\hline $\begin{array}{l}\text { How confident are you in your knowledge of } \\
\text { dispersion in optical fibers? }\end{array}$ & 2.68 & 2.14 \\
\hline $\begin{array}{l}\text { How confident are you in your knowledge of optical } \\
\text { power budgets? }\end{array}$ & 3.46 & 2.04 \\
\hline $\begin{array}{l}\text { How confident are you in your knowledge of } S / N \text { ratio } \\
\text { and Bit-Error Rate applied to optical systems? }\end{array}$ & 2.93 & 2.79 \\
\hline $\begin{array}{l}\text { How confident are you in your knowledge of optical } \\
\text { amplification (for extension work to longer links)? }\end{array}$ & 3.75 & 3.14 \\
\hline $\begin{array}{l}\text { How confident are you in your knowledge of } \\
\text { SONET/SDH standards? }\end{array}$ & 4.39 & 2.50 \\
\hline $\begin{array}{l}\text { How confident are you in your knowledge of } \\
\text { Wavelength Division Multiplexing (for extension work } \\
\text { to upgraded systems)? }\end{array}$ & 3.25 & 2.68 \\
\hline \multicolumn{3}{|l|}{ Key to mean values: } \\
\hline 1-2 Very confident to confident & & \\
\hline 2-3 Confident to somewhat confident & & \\
\hline 3-4 Somewhat confident to not very confident & & \\
\hline 4-5 Not very confident to not confident at all & & \\
\hline
\end{tabular}

of learning as a conversation between participants, where knowledge is gathered and shared among communities of learners [17]. The sharing of knowledge among group members was widely observed; however, it was clear that the students required time to acclimatize to the new approach. When they were asked during one of the focus groups how they managed individual topics and tasks associated with a given problem, some students expressed a lack of confidence in their ability to engage with the problems in a holistic sense. This was largely attributed to their delegation of tasks to individual group members accompanied by a perceived lack of knowledge transfer between individual members. This phenomenon was exemplified in one student's comment on the management of tasks during one particular problem:

"They are quite different tasks, so if some person is doing something completely different to you, there's no reason why you should sort of learn it."

The learning environment played an important role in promoting collaboration within and between groups. The provision of a number of whiteboards for student use during time-tabled sessions allowed collective engagement in the problem-solving process and shared information and progress between different groups, promoting teachback as individual students explained information that they had added. This approach also promoted a more holistic understanding of a given problem, as groups collectively used the facilities to test information and theories gathered at an individual level, and can go some way toward encouraging collaborative learning.

\section{CONCLUSION}

From the results of this study, it is concluded that the PBL approach can be highly effective in encouraging the development of the transferable skills that are valued by employers. In particular, staff observed students becoming adept at group working and enhancing their communications skills by engaging in the practices associated with PBL. More traditional curricula do not necessarily provide this kind of development that is clearly appreciated by the students as relevant and helpful for their future careers. As the pressures increase to redesign courses to reflect employer engagement and concerns, PBL can be an appropriate vehicle to ensure adequate attention is paid to both curriculum content and the processes by which students become effective lifelong learners. However, it is noted that problems need to be carefully constructed if students are to achieve a balance of broad topic coverage with in-depth analysis.

While the authors caution against direct comparison of assessment scores, due to the very different nature of the assessment regime from the traditional to the PBL model, the enhanced achievement is notable. Perkins [18] suggests that both engendering motivation in learning and especially developing the ability to deploy what he terms "proactive knowledge" should be a goal of contemporary higher education. By eradicating failure on the module through the radical redesign of assessment methods and practice, which placed greater emphasis on formative, group, and process-related assessment, it is suggested that student motivation may be enhanced over time. The opportunity to use the subject knowledge gained in the module actively and to apply it to a range of challenging problems is more likely to encourage 
such proactive deployment in ways that traditionally taught and examined curricula cannot. The move from traditional unseen examination to a balance of formative and summative assessment gives students a positive sense of their achievements during the course of study while they still have the opportunity to address any weaknesses.

If student achievement, through acting on feedback from formative activities, is greatly enhanced, and given that PBL encourages the development of transferable skills, there is also the potential for students to recognize a further significant benefit for their future development. By being provided with "non-expert" facilitation rather than direct teaching, students can begin to appreciate the contingent nature of knowledge and the beneficial processes of collaborative learning, including with their tutors, in the style of Pask's conversational framework.

Overall, both staff and students recognized PBL as a rewarding experience. However, it must be noted that, for students, the uncertainty introduced by problems with no single solution and the need for interpretation leads to anxiety, while the loss of precise control of direction, the need for careful use of language, and the development of appropriate problem staging can lead to similar anxiety in staff.

\section{ACKNOWLEDGMENT}

The authors thank colleagues at the University of Manchester and the University of Bristol for their helpful and enlightening discussions during the pilot project.

\section{REFERENCES}

[1] N. Spinks, N. Silburn, and D. Birchall, "Educating engineers for the 21st century," Royal Academy of Engineering, 2007 [Online]. Available: www.raeng.org.uk/education/ee21c/

[2] T. W. Hissey, "Enhanced skills for engineers (Pt. 2): Technical expertise alone is not enough," Proc. IEEE vol. 88, pp. 1367-1670, Aug. 2000.

[3] N. Entwistle, J. Nisbet, and A. Bromage, "Electronic engineering: Subject overview report," ETL Project, 2005 [Online]. Available: www.ed.ac.uk/etl

[4] J. Case, "Alienation and engagement: Exploring students' experiences of studying engineering," Teach. Higher Educ., vol. 12, no. 1, pp. 119-133, 2007.

[5] "Institution for Electrical Engineers working group report," IEE IWP, IEE, London, U.K.

[6] J. Biggs, Teaching for Quality Learning. Buckingham, U.K.: SRHE/ Open Univ. Press, 1999.

[7] A. Mantri, S. Dutt, J. P. Jupta, and M. Chitkara, "Design and evaluation of a PBL-based course in analog electronics," IEEE Trans. Educ., vol. 51, no. 4, pp. 432-438, Nov. 2008.

[8] J. E. Mitchell, J. Smith, and A. J. Kenyon, "It's not for lazy students like me...," Int. J. Elect. Eng. Educ., vol. 42, no. 1, pp. 41-51, 2005.

[9] J. E. Mitchell and J. Smith, "A case study of the introduction of problem-based learning in electronic engineering," Int. J. Elect. Eng. Educ., vol. 45, no. 1, pp. 131-143, 2008.
[10] E. De Graff, "The impact of assessment on the problem-based learning process," in Challenging Research in Problem-Based Learning-Illuminating Perspectives, Savin-Baden and Wilkie, Eds. Maidenhead, U.K.: Open Univ. Press, 2004.

[11] C. E. Hmelo, T. Shikano, M. Realff, B. Bras, J. Mullholland, and J. A. Vanegas, "A problem-based course in sustainable technology," in Proc. FIE Conf., 1995, vol. 2, pp. 4a3.1-4a3.5.

[12] L. R. J. Costa, M. Honkala, and A. Lehtovuori, "Applying the problembased learning approach to teach elementary circuit analysis," IEEE Trans. Educ., vol. 50, no. 1, pp. 41-48, Feb. 2007.

[13] S. A. West, "Objectives in response to students' uncertainty in a preclinical problem-based learning curriculum," Educ. Health, vol. 11, pp. 343-347, 1998.

[14] F. Biley, "Creating tension: Undergraduate student nurses response to a PBL Curriculum," Nurse Educ. Today, vol. 19, pp. 586-591, 1999.

[15] G. D. Hendry, G. Ryan, and J. Harris, "Group problems in problembased learning," Med. Teacher, vol. 25, no. 6, pp. 609-616, 2003.

[16] E. Wenger, Communities of Practice. Cambridge, U.K.: Cambridge Univ. Press, 1998.

[17] G. Pask, Conversation, Cognition, and Learning. New York: Elsevier, 1975.

[18] D. Perkins, "Beyond understanding," in Threshold Concepts Within the Disciplines, R. Land, J.H.F. Meyer, and J. Smith, Eds. Rotterdam, The Netherlands: Sense Publishers, 2008.

John E. Mitchell (S'96-M'00) received the B.Eng. and Ph.D. degrees in electronic engineering from University College London (UCL), London, U.K., in 1996 and 2000, respectively.

In 1999, he became a Research Fellow in the Department of Electronic and Electrical Engineering, UCL, becoming a Lecturer and Senior Lecturer in 2000 and 2006, respectively. He has published over 60 papers in the area of optical communications. He has been active in promoting innovation in teaching and has been involved in projects to bring problem-based learning, and more recently scenario-based learning, into the curriculum for electronic and electrical engineering. His research interests include optical access technologies, the transport of millimeter-wave radio signals over optical fiber for communications, and noise relating to crosstalk in optical networks.

Dr. Mitchell is a Member of the Institute of Engineering and Technology (IET) and the IEEE Education, Photonics, and Communications Societies.

Brian Canavan received the first-class Bachelor of Technological Education degree from the University of Glasgow, Glasgow, U.K., in 1997 and the Ph.D. degree from the university's Faculty of Engineering in 2007.

He is currently a Lecturer at the Robert Clark Centre for Technological Education, University of Glasgow. He has a range of experience in academic research, including the evaluation of learning technologies, problem-based learning, and reflective practice. He currently lectures in design on a number of undergraduate courses and supervises various post-graduate students at the Master's and Ph.D. level. He previously worked for a number of years in the field of electrical engineering design for a variety of industrial sectors including shipbuilding, petrochemical, and pharmaceutical.

Jan Smith received the B.Sc. (Hons.) degree in education technology from the University of East London, London, U.K., in 1999. She is currently completing the Ph.D. degree in education at the University of Strathclyde, Glasgow, U.K.

She is a Lecturer in the Centre for Academic Practice and Learning Enhancement, University of Strathclyde. She has worked on a number of curriculum development projects at universities in London and has research interests in educational development, e-learning, and problem-based learning.

Miss Smith is a Fellow of the Higher Education Academy and a Member of the Staff and Educational Development Association. 